Научная статья

УДК 8:008.001

DOI: $10.18101 / 2305-459 X-2020-3-71-78$

\title{
К ВОПРОСУ О МЕДИЦИНСКИХ ТЕРМИНАХ В СОЧИНЕНИИ Д. ЕНДОНОВА (1870-1937?)
}

\author{
(с) Цыренова Номинь Дондоковна \\ младший научный сотрудник, \\ Институт монголоведения, буддологии и тибетологии СО РАН \\ 670047, Россия, г. Улан-Удэ, ул. Сахьяновой, 6 \\ nomin_n@mail.ru
}

\begin{abstract}
Аннотация. Статья посвящена исследованию рукописных заметок бурятского эмчи-ламы Дондуба Ендонова, одним из выдающихся представителей бурятских эмчи-лам первой трети XX в., который имел высокую монашескую степень габжаламы и впоследствии возглавил тибетскую медицинскую школу при Ацагатском дацане. Рукопись хранится в коллекции монгольского фонда Центра восточных рукописей и ксилографов ИМБТ СО РАН. Для исследователей рукопись представляет интерес не только как медицинский источник, но и как объект лингвистического изучения. Данное сочинение было написано на классической монгольской письменности в 1935 г. В нашей работе рассматриваются некоторые специфические черты бурят-монгольской медицинской терминологии, используемой автором в его заметках по традиционной восточной медицине. Для решения поставленных задач используются сравнительно-сопоставительный метод, метод наблюдения.
\end{abstract}

Ключевые слова: Дондуб Ендонов; рукопись; классическая монгольская письменность; тибетская медицина; терминология.

Благодарность. Работа выполнена в рамках государственного задания: проект "Памятники письменности народов Внутренней Азии: исследование, перевод и презентация", № АААА-А19-119111300043-4

\section{Для цитирования}

Цыренова Н. Д. К вопросу о медицинских терминах в сочинении Д. Ендонова (1870-1937?) // Вестник Бурятского государственного университета. Язык. Литература. Культура. 2020. Вып. 3. С. 71-78.

\section{Введение}

В процессе распространения буддизма среди бурят в XVIII в. широкую популярность обрела и традиционная тибетская медицина. До 1923 г., когда была образована система здравоохранения в Бурят-Монгольской АССР, лекари эмчи-ламы оказывали медицинскую помощь населению, обучали хувараков в медицинских школах (бур. мамба / манба дацан) при крупнейших монастырях, однако часть из них осуществляла лечебную деятельность без специальной подготовки, руководствуясь личным опытом.

Одна из таких школ располагалась в Ацагатском дацане, основанном в 1825 г., а в 1831 г. школа получила официальное утверждение иркутского губернатора. После Октябрьской революции, в 1925 г. в рамках реализации решения 
II съезда бурятского духовенства тибетскую школу при Ацагатском дацане преобразовали в светскую медицинскую школу. В ней обучались миряне и ламы, велось преподавание европейской анатомии, физиологии и методов диагностики. При этом обязательным условием приема в данную школу было наличие свидетельства об окончании общеобразовательной начальной школы, а также знание тибетского языка [2, с. 66-67]. С 1926 г. именно Дондуб Ендонов был назначен председателем комитета объединенной школы тибетской медицины всех дацанов $^{1}$, или Ацагатского тибетско-медицинского комитета [5, с. 91].

В архивной коллекции Музея истории Бурятии имени М. Н. Хангалова хранится подборка документов, имеющих непосредственное отношение к Дондубу Ендонову, а именно: его личное дело, различные удостоверения личности, справки о командировках, письма, сведения о его пациентах, корреспонденция и финансовые документы, благодаря которым были установлены отдельные сведения о его жизненном пути. Согласно самому раннему документу, датированному 1900 г., Ендонов родился в 1870 г. в селе Курба (ныне территория Заиграевского района Республики Бурятия). Поскольку в одном из документов указывается, что он был ламой, соблюдавшим все необходимые обеты, то, по всей видимости, он по сложившимся традициям бурятских семей обучался с 7 лет в дацане. В 1897 г., в 27-летнем возрасте Д. Ендонов начал свою врачебную деятельность. Мы предполагаем, что до этого времени он прошел полный курс буддийской философии, который, как правило, продолжался более 20 лет. Свидетельством этому служит то, что в 1924 г. у него была высокая ученая степень габжа-ламы Ацагатского дацана [7, с. 10].

\section{Описание рукописи Д. Ендонова}

В богатой коллекции монгольского фонда Центра восточных рукописей и ксилографов Института монголоведения, буддологии и тибетологии (ЦВРК ИМБТ СО РАН) хранится большое количество оригинальных медицинских сочинений тибетских и монгольских авторов. Найденная среди них уникальная рукопись по теории и практике тибетской медицины бурятского эмчи-ламы Дондуба Ендонова в виде небольших заметок и сегодня не утратила своей ценности и вызывает несомненный интерес у исследователей.

Полное название работы Ендонова в оригинале звучит следующим образом:

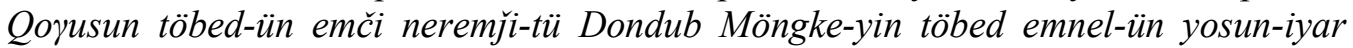
emčilelge-yin tuqai-du ebedčin eldeb jüil-üd-tü em ögtügsen temdeg-tü bičig dangča

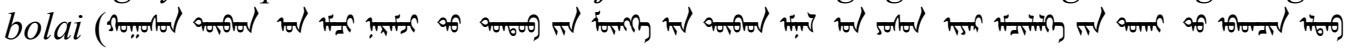

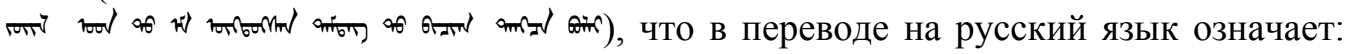
«Заметки о лечении различных заболеваний лекарственными средствами тибетской медицины известного тибетского врача Дондуба Мунхын».

Настоящее сочинение написано аккуратным почерком на монгольской письменности с использованием чернил черного (основной текст) и красного

${ }^{1}$ В 1925 г. на повестке дня II съезда бурятского духовенства обсуждалось положение тибетской медицины при дацанах, школах и их объединение в единую школу с центром в Ацагатском дацане или по месту расположения школы: при Ацагатском аршане. 
(вставки на тибетском языке) цветов, состоит из 49 листов, сброшюрованных в виде тетради размером $17 \mathrm{x} 20,3 \mathrm{~cm}$. Текст расположен на обеих сторонах листа по вертикали, бумага желтоватая, не подвергалась механическому воздействию. Пагинация тибетскими цифрами проставлена только на первых двух листах.

Д. Ендонов начинает свои заметки с упоминания известного бурятского этнографа-собирателя Генин-Дармы Нацова (1901-1942), который предложил ему написать об опыте личной врачебной практики. Согласно авторскому колофону, рукопись была им закончена 10 февраля 1935 г. (töbed emši nerem ǰi-tü Dondubebügen Möngke-yin 1935 onи febarali 10 edür-e tegüsbe). В свою работу Д. Ендонов включил многочисленные вставки на тибетском языке, которые касаются преимущественно названий отдельных заболеваний, прописей по названиям лекарств, а также большой пласт лексики из бурятского языка. В процессе исследования нами был сделан вывод о том, что источниковой базой этого сочинения послужил известный тибетский медицинский трактат «Чжуд-ши» (монг. Дөрвөн үндсэн) [11], который был отредактирован тибетским ученым Ютокпа Йонтен Гонпо младшим (1126 г. р.) [9, с. 159], а также комментарии к нему - «Лхантаб» [8, с. 147], составленный тибетским ученым по имени Деси Сангье Гьяцо в 1691 г. Сходство структур разделов рукописи Д. Ендонова и монголоязычного «Лхантаба» позволяет утверждать, что в большей степени автор придерживался основы «Лхантаб».

\section{Анализ некоторых медицинских терминов рукописи}

Хотя в структурном плане сочинение берет за основу вышеупомянутый тибетский медицинский канон «Чжуд-ши», описание многих заболеваний эмчилама снабжает личными замечаниями и примечаниями, в которых можно усмотреть следы индивидуального подхода лекаря, а также его наблюдения из врачебной практики.

Следует отметить, что в своих заметках автор не придерживался общепринятых правил написания тех или иных слов на монгольской письменности, бурятские слова передавал через монгольскую графику, таким образом, возникли так называемые бурятизмы. К примеру:

Таблица 1

\begin{tabular}{|c|c|c|c|c|c|}
\hline $\begin{array}{l}\text { В тексте Д. } \\
\text { Ендонова: }\end{array}$ & $\begin{array}{l}\text { современное } \\
\text { написание } \\
\text { [13]: }\end{array}$ & $\begin{array}{l}\text { перевод на } \\
\text { русском } \\
\text { языке: }\end{array}$ & $\begin{array}{l}\text { на бурятском } \\
\text { языке [4]: }\end{array}$ & $\begin{array}{l}\text { на монголь- } \\
\text { ском языке }\end{array}$ & $\begin{array}{l}\text { страницы } \\
\text { рукописи }\end{array}$ \\
\hline $\begin{array}{c}\text { yümürkei } \\
\text { sutwann }\end{array}$ & iberkei मिक्ति & грыжа & Юмэрхэй & ивэрхий & л. 44 \\
\hline joqulqu जाणोime & 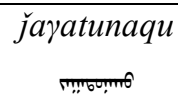 & чесаться & зохолхо & загатнах & л. 4 \\
\hline satula trowl & čadqu & наедаться & садаха & цадах & л. 9 \\
\hline 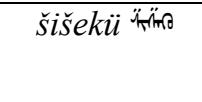 & 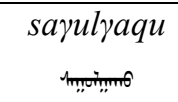 & понос & Шэшэхэ & чацга алдах & л. 4 \\
\hline
\end{tabular}


ВЕСТНИК БУРЯТСКОГО ГОСУДАРСТВЕННОГО УНИВЕРСИТЕТА. ЯЗЫК. ЛИТЕРАТУРА. КУЛЬТУРА

\begin{tabular}{|c|c|c|c|c|c|}
\hline 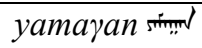 & 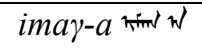 & коза & ямаан & ямаа & л. 43 \\
\hline eryekü काष & ergikü thre & кружиться & эрьехэ & эргэх & л. 2 \\
\hline oladqu totume & oladaqu & $\begin{array}{c}\text { оказы- } \\
\text { ваться } \\
\text { больше, } \\
\text { чем надо }\end{array}$ & олодохо & олдох & л. 22 \\
\hline
\end{tabular}

Подчеркиваем, что «бурятизмы» присущи не только этому конкретному тексту, их можно встретить в летописях, архивных документах и т. д., написанных рукой бурята [6].

Обширное использование медицинских терминов в данном труде представляет богатейший материал прежде всего для филологического исследования. Дело в том, что большинство слов на монгольском языке имеют несколько значений, в контексте перевода медицинского сочинения могут обозначать какой-либо термин, а в общеупотребительном значении передавать совершенно другое понятие. Например, слово saba но в контексте перевода текста медицинского характера имеет несколько специальных значений, а именно: 1) матка; 2) полые органы (сердце, печень, легкие, желудок, почки, желчный пузырь, кишечник, мочевой пузырь и семенник), а в обычном контексте имеет значение 'вместилище, хранилище; помещение; посуда, сосуд, емкость' [1, с. 7]. Из данных примеров можно предположить, что некоторые монгольские медицинские термины возникли на основе образной бытовой лексики.

В своем сочинении Дондуб Ендонов при обозначении лечебных действий и процедур употребил несколько различных синонимических вариантов, которые представлены ниже в таблицах. Здесь наблюдаем широкое разнообразие использования глагола 'лечить' на монгольском языке (анагаax, засах, эдэгээx, аргалах, арга хийх, өвчин арилгах).

Таблий 2

\begin{tabular}{|c|c|c|c|}
\hline № & транслитерация & перевод & $\begin{array}{l}\text { страницы в } \\
\text { рукописи }\end{array}$ \\
\hline 1 & anaraqu & $\begin{array}{l}\text { исцелять, вылечивать, лечить, прини- } \\
\text { мать на лечение }\end{array}$ & л. 6 \\
\hline 2 & ǰasaqu & $\begin{array}{l}\text { 1) устраивать, приводить в порядок; управ- } \\
\text { лять; } \\
\text { 2) исправлять, поправлять; корректировать; } \\
\text { налаживать; ремонтировать; } \\
\text { 3) кастрировать, оскопить, холостить; } \\
\text { 4) лечить, оперировать }\end{array}$ & л. 9 \\
\hline 3 & edegekü & вылечить & л. 11 \\
\hline 4 & arjalaqu & $\begin{array}{l}\text { 1) изыскивать возможность, средства; нахо- } \\
\text { дить, выход, способ; }\end{array}$ & л. 12 \\
\hline
\end{tabular}




\begin{tabular}{|l|l|l|c|}
\hline \multicolumn{1}{|l|}{} & $\begin{array}{l}\text { 2) выкинуть финт, трюк, умудряться, из- } \\
\text { ловчиться, ухищряться; маневрировать; } \\
\text { 3) подлечиваться, применять методы } \\
\text { лечения }\end{array}$ & \\
\hline 5 & ary-a kikü & $\begin{array}{l}\text { 1) употреблять способ, применять прием; } \\
\text { применять средство, ухитряться; ловко при- } \\
\text { норавливаться, прибегать к маневру, манев- } \\
\text { рировать; } \\
\text { 2) найти способ, метод лечения; принять } \\
\text { меры по лечению }\end{array}$ & \\
\hline 6 & ebedcin-i arilyaqu & вылечить, излечить; «очистить» болезнь & л. 25 \\
\hline
\end{tabular}

Кроме этого, важно отметить, что автором используется ряд отдельных терминов для обозначения действий, связанных с лечением или возникновением болезни. В нижеприведенной таблице видим, что некоторые медицинские термины основаны на простых глаголах из бытовой лексики.

Таблица 3

\begin{tabular}{|c|c|c|c|}
\hline № & термин & $\begin{array}{l}\text { прямое значение термина и его пояснение в медицин- } \\
\text { ском контексте }\end{array}$ & $\begin{array}{c}\text { страницы в } \\
\text { рукописи }\end{array}$ \\
\hline 1 & 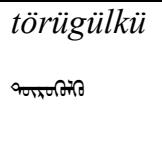 & $\begin{array}{l}\text { в прямом значении: рождать, рожать, давать жизнь, } \\
\text { вызывать (к жизни); порождать, создавать. } \\
\text { в тексте: создавать, порождать, быть причиной, усло- } \\
\text { вием появления или зарождения чего-либо }\end{array}$ & л. 26 \\
\hline 2 & tariqu & $\begin{array}{l}\text { в прямом значении: } \\
\text { 1) сеять, засевать; сажать; } \\
\text { в переносном значении: } \\
\text { 2) заражать; совершать проступок; } \\
\text { в тексте: зарождение новой болезни из-за запоздалого } \\
\text { лечения другой болезни } \\
\end{array}$ & л. 20 \\
\hline 3 & tarulyaqu & $\begin{array}{l}\text { значения совпадают: } \\
\text { 1) принимать слабительное средство; } \\
\text { 2) очищать кишечник слабительным, слабить }\end{array}$ & л. 9 \\
\hline 4 & sarulyaqu & $\begin{array}{l}\text { в прямом значении: } \\
\text { 1) заставлять сидеть, сажать; велеть сесть, посадить, } \\
\text { усадить, поселять, помещать; } \\
\text { 2) селить, расселять; переселять; } \\
\text { 3) сажать (рассаду); } \\
\text { в тексте: нести (о поносе); слабить; понос, кишечное } \\
\text { расстройство, диарея }\end{array}$ & л. 7 \\
\hline
\end{tabular}

Дондуб Ендонов в своей работе уделяет особое внимание разъяснению трех внутренних причин всех заболеваний, называемых в тибетском языке «три доша», в следующей таблице нами представлены монгольские эквиваленты этих терминов. 
Таблиия 4

\begin{tabular}{|c|c|c|}
\hline на тибетском языке & на монгольском языке & перевод \\
\hline рлунг & хии, kei & ветер \\
\hline мкхрис & шар, sir- $a$ का $\mathrm{W}$ & $\begin{array}{l}\text { желчь, в прямом зна- } \\
\text { чении: желтый цвет }\end{array}$ \\
\hline бад кан & 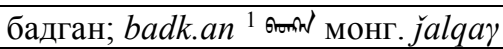 & слизь \\
\hline
\end{tabular}

Как было сказано выше, в сочинении Д. Ендонова встречаются термины, смысл которых расшифровывается в зависимости от контекста (табл. 5). В нижеприведенных примерах слов: sudal и sira обнаруживаем образование полисемии в монгольском языке.

Таблииа 5

\begin{tabular}{|c|c|c|c|}
\hline термин & значение & транслитерация & $\begin{array}{l}\text { страницы в } \\
\text { тексте }\end{array}$ \\
\hline \multirow[t]{4}{*}{$\begin{array}{l}\text { sudal } \\
\text { tobrt }\end{array}$} & 1. пищеводный канал & $\begin{array}{l}\text { idegen-ü yabuqu su- } \\
\text { dal }\end{array}$ & л. 14 \\
\hline & $\begin{array}{l}\text { 2. мед. нефридии (в прямом значении } \\
\text { 'почечный канал') }\end{array}$ & bögeri-yin sudal & л. 14 \\
\hline & 3. жизненный канал & amin sudal & Л. 20 \\
\hline & 4. пульс (от лат. pulsus - удар, толчок) & $\begin{array}{l}\text { sudal sula, alyur sib- } \\
\text { ingki }^{2}\end{array}$ & л. 36 \\
\hline \multirow{2}{*}{$\begin{array}{l}\text { sira } \\
4 \pi n+1\end{array}$} & жёлтый цвет & 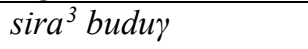 & л. 22 \\
\hline & 6. желчь & sira & л. 4 \\
\hline
\end{tabular}

Наряду с этими примерами важно отметить еще одну своеобразную особенность в тексте, связанную с обозначением легкости и сложности лечения того или иного заболевания. Для передачи тяжелоизлечимых болезней Д. Ендонов использует бурятское слово 'бэрхэ', которое переводится как с положительной коннотацией: 'опытный, умелый, способный, ловкий, отличный, очень хороший, лучший', так и в негативной окраске: 'трудный, труднопроходимый, тяжелый, тяжкий, обременительный; сложный, серьезный'. При обозначении легкоизлечимых заболеваний автор употребляет слово 'бэлэн', смысл которого несет положительную нагрузку и переводится как 1) готовый, приготовленный; 2) нетрудный, легкий, несложный.

В рукописи Д. Ендонов активно использует иноязычные слова: русизмы,

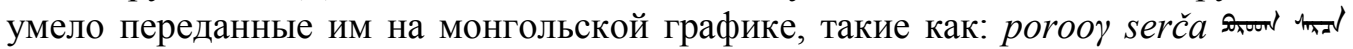

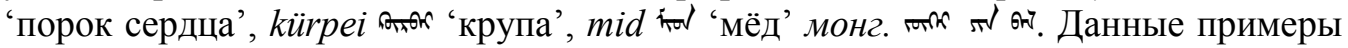
подтверждают, что автор владел познаниями в европейской медицине. Кроме

\footnotetext{
${ }^{1}$ В монголоязычном издании «Лхантаба» стоит слово badyan [7, с. 1].

2 'пульс слабый, медленный и вялый'.

${ }^{3}$ Монг. sira buduү “желтая краска".
} 
того, в заметках встречаются и тибетизмы: юor oor kemekü ebedčin 'болезнь ор'

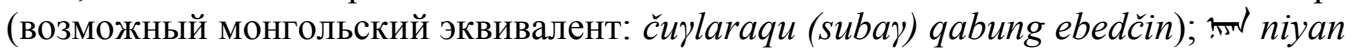
gniyan 'болезнь ньен', встречающийся в тексте в различных вариациях написания, на тибетском языке языке звучит как: тиб. gnyan khyung.

Таким образом, мы рассмотрели некоторые специфические особенности бурят-монгольской медицинской терминологии на примере сочинения Дондуба Ендонова, написанного в 1935 г.

Во-первых, в тексте рукописи нами выявлена самобытная система медицинских терминов, вобравшая в себя достижения тибетской традиционной медицины.

Во-вторых, нами установлено, что источниковой базой исследуемого письменного памятника послужил известный тибетский трактат «Чжуд-ши», в большей степени за основу был взят монгольский «Лхантаб» - комментарии к «Чжуд-ши».

В-третьих, нами выяснено, что многие монгольские медицинские термины основаны на бытовой лексике, используемой носителями в ежедневных делах.

\section{Литература}

1. Рукопись Дондуб Ендонова: «qоүusun töbed-ün emči neremji-tü Dondub Möngkeyin töbed emnel-ün yosun-iyar emčilelge-yin tuqai-du ebedčin eldeb jüil-üd-tü em ögtügsen temdeg-tü bičig dangča bolai» // Шифр хранения ЦВРК ИМБТ СО РАН: БМ-489.

2. Ангаева С. П. Буддизм в Бурятии и Агван Даржиев. Улан-Удэ: Бурятское книжное изд-во, 1999. $140 \mathrm{c}$.

3. Большой академический монгольско-русский словарь / отв. ред. Г. Ц. Пюрбеев. M.: Academia, 2001. 2198 c.

4. Бурятско-русский словарь / ред. К. М. Черемисов. М.: Советская энциклопедия, 1973. $803 \mathrm{c}$.

5. Ванчикова Ц. П., Жабон Ю. Ж. Характеристика и классификация письменного наследия Д. Ендонова (1870-1937?) // Гуманитарный вектор. 2019. Вып. Т. 14, № 3. С. 89-97. DOI: 10.21209/1996-7853-2019-14-3-89-97

6. Ван И.Д. Цыренова Н.Д. Бурятские народные песни в рукописи летописца Даши Бубеева // Эпос "Гэсэр" - духовное наследие народов Центральной Азии: сборник междунар. науч. конф. 2020. С. 208-211.

7. Ендонов Д. Практические заметки бурятского эмчи-ламы по тибетской медицине / введение, исследование, перевод с монгольского, комментарий, транслитерация и факсимиле текста Ц. П. Ванчикова [и др.]; отв. ред. И. Э. Матханов. Улан-Удэ: Домино, 2019. 166 с.: ил. IBSN 978-5-7925-0563-6.

8. Жабон Ю. Ж. Тибетские комментарии к «Чжуд-ши» // Вестник Бурятского научного центра Сибирского отделения Российской академии наук. 2015. Вып. № 8(13). C. 145-148. doi: 10.18097/1994-0866-2015-0-8-145-148.

9. Жабон Ю. Ж. Тибетские источники о распространении "Чжуд-ши" // Вестник Бурятского государственного университета. 2011. № 8. С. 157-161.

10. Лхантаб / сост. Томур. Хух-хото: Жэньминь чубаньшэ, 1987. 883 с.

11. «Чжуд-ши»: Канон тибетской медицины / пер. с тиб., предисл., примеч., указатели Д. Б. Дашиева; отв. ред. С. М. Николаев. М.: Восточная литература РАН, 2001. 766 с. ISBN 5-02-018033-5.

12. Очирова Ц.-Х. В. Реконструкция биографии Дондуба Ендонова — руководителя тибетской медицинской школы при Ацагатском аршане (по материалам Музея истории 
Бурятии) // Культура Центральной Азии: письменные источники. Улан-Удэ, 2004. Вып. 6. C. $126-136$.

13. Учебный словарь монгольского языка / под ред. Э. Буян-Улзы. Хух-хото: Изд-во «Нэй мэнгу жэньминь чубаньшэ», 2015. 1458 с.

\title{
ON MEDICAL TERMS IN THE WORKS \\ OF D. ENDONOV (1870-1937?)
}

\author{
Nomin D. Tsyrenova \\ Junior Researcher, \\ Institute for Mongolian, Buddhist and Tibetan Studies SB RAS \\ 6 Sakhyanovoy St., Ulan-Ude 670047, Russia \\ E-mail:nomin_n@mail.ru
}

Abstract. The article is devoted to the study of handwritten notes of the Buryat Emchi Lama Dondub Endonov, one of the outstanding representatives of the Buryat Emchi Lamas of the first third of the XX century, who had a high monastic degree of Gabja Lama, and subsequently headed the Tibetan Medical School at the Atsagatsky Datsan. The manuscript is kept in the collection of the Mongolian fund of the Center for Oriental Manuscripts and Xylographs of the Institute of International Biology and Biology SB RAS. For researchers, the manuscript is of interest not only as a medical source, but also as an object of linguistic study. This essay was written in the classical Mongolian script in 1935. In our work, we consider some specific features of the Buryat-Mongolian medical terminology used by the author in his notes on traditional oriental medicine. To solve the set tasks, the comparative-comparative method, the observation method, are used. The article is intended for a wide range of readers.

Keywords: Dondub Endonov; manuscript; classical Mongolian writing; Tibetan medicine; terminology.

Статья поступила в редакиию 26.10.2020; одобрена после рецензирования 13.11.2020; принята к публикации 01.12.2020. 